\title{
Diagnóstico de raiva no Rio Grande do Sul, Brasil, de 1985 a $2007^{1}$
}

\author{
Thais F. Teixeira², Carine L. Holz², Suzana P.M.B. Caixeta², Diógenes \\ Dezen², Samuel P. Cibulski ${ }^{3}$, Juliana Reis da Silva², Julio C.A. Rosa², \\ Eduardo Schmidt ${ }^{2}$, José C. Ferreira ${ }^{2}$, Helena B.C.R. Batista ${ }^{3}$, Eduardo \\ Caldas $^{4}$, Ana Cláudia Franco ${ }^{3}$ e Paulo M. Roehe ${ }^{2,3^{\star}}$
}

\begin{abstract}
Teixeira T.F., Holz C.L., Caixeta S.P.M.B., Dezen D., Cibulski S.P., Silva J.R., Rosa J.C.A., Schmidt E., Ferreira J.C., Batista H.B.C.R., Caldas E., Franco A.C. \& Roehe P.M. 2008. [Rabies diagnosis in the state of Rio Grande do Sul, Brazil, from 1985 to 2007.] Diagnóstico de raiva no Rio Grande do Sul, Brasil, de 1985 a 2007. Pesquisa Veterinária Brasileira 28(10):515-520. Instituto de Pesquisas Veterinárias Desidério Finamor, Fepagro-Saúde Animal, Cx. Postal 2076, Porto Alegre, RS 90001970, Brazil. E-mail: proehe@ufrgs.br

The results of 23 years of rabies diagnosis carried out at the Veterinary Research Institute Desidério Finamor, in the state of Rio Grande do Sul, RS, Brazil, are reported. From 1985 to 2007, a total of 23.460 specimens were examined, corresponding to $95 \%$ of the total number of samples submitted to rabies laboratory diagnosis notified within the state. Diagnostic methods included standard techniques such as the fluorescent antibody test (FAT) and mouse inoculation test (MIT). No cases of human rabies occurred in the period. Rabies virus (RV) was detected in 739 specimens (3.1\%), from which 656 $(88.7 \%)$ were from cattle. The virus was also identified in specimens from 23 dogs $(3.1 \%)$, 21 horses $(2.9 \%), 29$ bats $(4.0 \%), 4$ cats $(0.5 \%), 3$ sheep $(0.4 \%), 2$ pigs $(0.27 \%)$ and a wild animal of undetermined species $(0.13 \%)$. The last case of rabies associated with a canine variant was diagnosed in 1988. Two cases of rabies associated with bat variant viruses were reported, in a domestic cat (2001) and in a dog (2007). In cattle, a marked tendency to a decrease in the number of cases was detected in the examined period. In contrast, an increase in the number of cases in haematophagous as well as in non haematophagous bats is noticed. However, as the number of bat specimens submitted for diagnosis has increased, this finding most likely reflects a higher degree of awareness on the possible role for bats in the rabies transmission cycle, rather than any particular changes on the virus or its hosts.
\end{abstract}

INDEX TERMS: Rabies, epidemiology, diagnosis, incidence.

\footnotetext{
${ }^{1}$ Recebido em 8 de outubro de 2007.

Aceito para publicação em 5 de junho de 2008.

${ }^{2}$ Equipe de Virologia, Instituto de Pesquisas Veterinárias Desidério Finamor (IPVDF), Estrada do Conde 6000, Eldorado do Sul, Cx. Postal 2076, Porto Alegre, RS 90001-970, Brasil. *Autor para correspondência: proehe@gmail.com

${ }^{3}$ Laboratório de Virologia, Departamento de Microbiologia, ICBS, Universidade Federal do Rio Grande do Sul (UFRGS), Av. Sarmento Leite 500, sala 208, Porto Alegre, RS 90050-170.

${ }^{4}$ Centro Estadual de Vigilância em Saúde, Secretaria Estadual de Saúde do Estado do Rio Grande do Sul, Rua Domingos Crescêncio 132, Porto Alegre, RS 90650-090
}

RESUMO.- São apresentados os resultados de 23 anos de diagnósticos de raiva realizados no Instituto de Pesquisas Veterinárias Desidério Finamor, no Estado do Rio Grande do Sul, Brasil. Entre os anos de 1985 e 2007, um total de 23.460 amostras foram diagnosticadas no laboratório, compreendendo cerca de $95 \%$ do número total de amostras submetidas ao diagnóstico laboratorial de raiva no Estado. A metodologia utilizada seguiu técnicas padrões como a imunofluorescência direta (IFD) e inoculação em camundongos (IC). Não ocorreram casos de raiva humana no período. O vírus rábico (VR) foi detectado em 739 (3,1\%) amostras, 
sendo $656(88,7 \%)$ de origem bovina. O vírus foi também identificado em 23 caninos (3,1\%), 21 eqüinos (2,9\%), 29 quirópteros $(4,0 \%)$, 4 felinos $(0,5 \%), 3$ ovinos $(0,4 \%)$, 2 suínos $(0,27 \%)$ e em um animal selvagem de espécie indeterminada $(0,13 \%)$. O último caso de raiva em cães associado com variantes do vírus endêmicas nessa espécie foi diagnosticado em 1988. Dois episódios de contaminação incidental registrados em um felino em 2001 e em um canino em 2007, associados com variantes do vírus prevalentes em morcegos. Em relação à raiva bovina, os dados aqui apresentados revelam uma marcante diminuição no número de casos de raiva nessa espécie, em comparação com registros prévios. Por outro lado, um aumento no número de casos de raiva em morcegos hematófagos e não hematófagos vem sendo observado; no entanto, não é possível associar este aumento com modificações nas relações vírus/hospedeiro, pois o número de morcegos submetidos para diagnóstico tem igualmente aumentado. Isto provavelmente reflete o aumento do conhecimento sobre o papel de morcegos no ciclo de transmissão, e não necessariamente alterações no vírus e/ou nos hospedeiros.

TERMOS DE INDEXAÇÃO: Raiva, epidemiologia, diagnóstico, incidência.

\section{INTRODUÇÃO}

Um sistema de diagnóstico adequado é essencial para o monitoramento da evolução da infecção e suas interações com os hospedeiros. Em relação à raiva, a importância do diagnóstico é ainda mais evidente, uma vez que a correta identificação da infecção tem sérias implicações na profilaxia e tratamento de pessoas expostas. Metodologicamente, o diagnóstico da raiva compreende um conjunto de técnicas padronizadas, as quais são utilizadas na maioria dos laboratórios do mundo (Dean et al. 1996, Kaplan et al. 1996, Koprowski 1996). No Rio Grande do Sul, o diagnóstico laboratorial de raiva é oficialmente realizado no Instituto de Pesquisas Veterinárias Desidério Finamor (IPVDF), órgão da Fundação Estadual de Pesquisa Agropecuária (Fepagro).

O levantamento aqui reportado apresenta os resultados dos diagnósticos de raiva realizados no período de 1985 a 2007. A intenção do presente trabalho é apresentar os dados de forma a permitir a visualização da evolução temporal da situação epidemiológica da enfermidade no Estado nesse período.

\section{MATERIAL E MÉTODOS}

Amostras. Para os fins deste estudo, as amostras foram separadas de acordo com as espécies de origem (Quadro 1). Os tecidos submetidos para exame consistiam essencialmente de encéfalos inteiros ou fragmentos destes. Ocasionalmente foram submetidos cadáveres inteiros, os quais foram necropsiados e amostras de tecido encefálico foram coletadas no próprio laboratório. Sempre que possível, foram coletados fragmentos de cornos de Amon, córtex cerebral e cerebelo para os exames laboratoriais.

Coleta de dados. Os diagnósticos de raiva realizados no
Quadro 1. Amostras submetidas ao diagnóstico de raiva no Instituto Desidério Finamor, Eldorado do Sul, RS, no período de 1985-2007

\begin{tabular}{|c|c|c|c|c|}
\hline Espécies & $\begin{array}{c}\text { Positivo } \\
\text { (n) }\end{array}$ & $\begin{array}{c}\text { Negativo } \\
\text { (n) }\end{array}$ & $\begin{array}{l}\text { Impróprio } \\
\text { (n) }\end{array}$ & $\begin{array}{c}\text { Total } \\
(\mathrm{n})\end{array}$ \\
\hline Caninos (Canis lupus familiaris) & 23 & 16883 & 131 & 17037 \\
\hline Felinos (Felis sylvestris catus) & 4 & 2456 & 22 & 2482 \\
\hline Bovinos (Bos taurus) & 656 & 1085 & 41 & 1782 \\
\hline Morcegos (Chiroptera) & 29 & 1724 & 15 & 1768 \\
\hline Eqüinos (Equidae) & 21 & 126 & 3 & 150 \\
\hline Ovinos (Ovis aries) & 3 & 34 & 0 & 37 \\
\hline Suínos (Sus sp.) & 2 & 34 & 4 & 40 \\
\hline $\begin{array}{l}\text { Animal Silvestre } \\
\text { (sp. não identificada) }\end{array}$ & 1 & 0 & 0 & 1 \\
\hline Hamster (Cricetinae) & 0 & 22 & 0 & 22 \\
\hline Primatas não humanos & 0 & 36 & 2 & 38 \\
\hline Bubalino (Bubalus sp.) & 0 & 4 & 0 & 4 \\
\hline Leão (Panthera leo) & 0 & 1 & 0 & 1 \\
\hline Esquilo (Sciuridae) & 0 & 2 & 0 & 2 \\
\hline Coelho (Leporidae) & 0 & 10 & 0 & 10 \\
\hline Humano (Homo sapiens sapiens) & 0 & 1 & 0 & 1 \\
\hline Cervídeo (Cervidae) & 0 & 2 & 0 & 2 \\
\hline Cobaio (Cavia sp.) & 0 & 1 & 0 & 1 \\
\hline Gambá (Didelphis sp.) & 0 & 12 & 1 & 13 \\
\hline Raposa (sp. não identificada) & 0 & 1 & 0 & 1 \\
\hline Furão (Mustela putorius furo) & 0 & 1 & 0 & 1 \\
\hline Gerbil (Gerbillinae) & 0 & 1 & 0 & 1 \\
\hline Preá (Cavia aperea) & 0 & 1 & 0 & 2 \\
\hline Quati (Nasua sp.) & 0 & 2 & 0 & 2 \\
\hline Tatu (Dasypodidae) & 0 & 1 & 0 & 1 \\
\hline Leão marinho (Otaria flavescens) & 0 & 1 & 0 & 1 \\
\hline Rato (Rattus sp.) & 0 & 4 & 0 & 4 \\
\hline Roedor (sp. não identificada) & 0 & 10 & 1 & 11 \\
\hline Caprino (Capra aegagrus hircus) & 0 & 35 & 0 & 35 \\
\hline Graxaim (Pseudalopex gymnocercus) & s) 0 & 10 & 0 & 10 \\
\hline Total & $\begin{array}{c}739 \\
(3,1 \%)\end{array}$ & $\begin{array}{c}22500 \\
(96,0 \%)\end{array}$ & $\begin{array}{c}221 \\
(0,9 \%)\end{array}$ & 23460 \\
\hline
\end{tabular}

período de janeiro de 1985 a dezembro de 2007 foram coletados pela consulta aos livros de registro do Setor de Raiva do Laboratório de Virologia do Instituto de Pesquisas Veterinárias Desidério Finamor (IPVDF, Fepagro).

Diagnóstico. $O$ diagnóstico de raiva foi realizado pelo uso da técnica de imunofluorescência direta (IFD) (Dean et al. 1996), utilizando-se conjugado anti-rábico fornecido pelo Instituto Pasteur, São Paulo. Os resultados da IFD foram confirmados por inoculação em camundongos lactentes (Koprowski 1996). Nos primeiros anos incluídos neste estudo ainda foi utilizado o método de Sellers para a detecção de corpúsculos de Negri (Mayr \& Guerreiro 1972) como método de diagnóstico complementar. Algumas amostras foram consideradas impróprias para o diagnóstico por terem sido remetidas em conservantes inadequados (formol, etanol, ou outros) ou por se encontrarem em estado adiantado de decomposição.

A partir de 1995 foram introduzidos métodos de análise antigênica com anticorpos monoclonais anti-lissavírus (Pantoja 1995), o que permitiu caracterizações antigênicas mais detaIhadas das amostras isoladas, incluindo a determinação da provável espécie de origem (ou provável hospedeiro natural de origem) das amostras isoladas (Roehe et al. 1997). Em 2001 foram introduzidas metodologias de análise genômica, como a transcrição reversa/reação da polimerase em cadeia (RT-PCR), sendo os produtos destas submetidos à restrição enzimática $\mathrm{e}$ seqüenciamento de nucleotídeos correspondentes a fragmen- 
tos da região codificante da proteína $\mathrm{N}$ do vírus (Schaefer et al. 2005), permitindo assim análises das características genômicas das amostras isoladas.

\section{RESULTADOS}

O Quadro 1 apresenta os resultados dos diagnósticos realizados, por espécie animal, no período considerado. Assim, nos 23 anos compreendidos neste levantamento, 23.460 amostras foram examinadas, o que compreende a 95\% do diagnóstico laboratorial de raiva no Rio Grande do Sul (Quadro 2).

Os casos de raiva diagnosticados no período de 19852007 estão apresentados no Quadro 3. Não foram relatados casos de raiva humana no período. Das 739 amostras positivas, a maioria, $656(88,7 \%)$ era de origem bovina. A infecção pelo vírus rábico foi também detectada em 23 ca- ninos (3,1\%), 21 eqüinos (2,9\%), 29 quirópteros (4,0\%), 4 felinos ( $0,5 \%)$, 3 ovinos $(0,4 \%)$, 2 suínos $(0,27 \%)$ e $1(0,13 \%)$ de um animal selvagem de espécie indeterminada.

A raiva em caninos se manteve em caráter endêmico no Estado até 1988. Em 1990 ocorreu um caso isolado de raiva em um felino, cuja fonte de infecção não foi possível determinar, em função dos métodos disponíveis à época (vide discussão, abaixo). Em 2001, 11 anos após o último episódio de infecção de um felino, foi identificado um novo caso em um gato. Neste evento, porém, foi possível determinar com precisão a fonte de infecção, comprovadamente uma variante de VR de origem de morcegos não hematófagos (Schaefer et al. 2002). Em 2007 ocorreu um caso em um cão no município de Tapes, no qual igualmente foi identificada uma variante de VR de origem de morcegos insetívoros (Batista et al. 2008).

Quadro 2. Amostras submetidas ao diagnóstico de raiva no Estado do Rio Grande do Sul, no período de 1985-2007

\begin{tabular}{|c|c|c|c|c|c|c|c|c|c|c|}
\hline \multirow[t]{3}{*}{ Espécies } & \multicolumn{9}{|c|}{ Diagnóstico laboratorial } & \multirow{3}{*}{$\begin{array}{l}\text { Diagnóstico } \\
\text { Clínico }\end{array}$} \\
\hline & \multicolumn{3}{|c|}{ Capital } & \multicolumn{3}{|c|}{ Interior } & \multicolumn{3}{|c|}{ Estado } & \\
\hline & Pos. & Neg. & Total & Pos. & Neg. & Total & Pos. & Neg. & Total & \\
\hline Humana & 0 & 1 & 1 & 0 & 0 & 0 & 0 & 0 & 0 & 0 \\
\hline Canina & 0 & 4888 & 4888 & 56 & 13706 & 13762 & 57 & 18654 & 18711 & 0 \\
\hline Felina & 0 & 923 & 923 & 12 & 1398 & 1410 & 12 & 2323 & 2335 & 0 \\
\hline Bovina & 6 & 67 & 73 & 664 & 992 & 1656 & 670 & 1059 & 1729 & 1071 \\
\hline Quiróptera & 5 & 171 & 176 & 20 & 1143 & 1163 & 24 & 1314 & 1338 & 114 \\
\hline Outras & 1 & 261 & 262 & 31 & 274 & 305 & 32 & 529 & 561 & 61 \\
\hline Total & 12 & 6311 & 6323 & 783 & 17513 & 18296 & 795 & 23879 & 24674 & 1246 \\
\hline
\end{tabular}

Fonte: SES/CEVS/Programa Estadual de Controle e Profilaxia da Raiva (PECPRaiva).

Quadro 3. Distribuição anual dos casos de raiva positivos diagnosticados no IPVDF no período de 1985- 2007

\begin{tabular}{|c|c|c|c|c|c|c|c|c|c|c|}
\hline Ano & Canino & Felino & Bovino & Quiróptero & Eqüino & Ovino & Suíno & $\begin{array}{l}\text { Animal } \\
\text { Silvestre/ }\end{array}$ & Total & Percentagem \\
\hline 1985 & 12 & 1 & 117 & 1 & 7 & 2 & 1 & - & 141 & 19,14 \\
\hline 1986 & 8 & - & 197 & 3 & 6 & 1 & - & - & 215 & 29,0 \\
\hline 1987 & 1 & 1 & 87 & - & 2 & - & - & 1 & 92 & 12,5 \\
\hline 1988 & 1 & - & 35 & - & 1 & - & 1 & - & 38 & 5,2 \\
\hline 1989 & - & - & 26 & - & - & - & - & - & 26 & 3,5 \\
\hline 1990 & - & 1 & 15 & - & 1 & - & - & - & 17 & 2,3 \\
\hline 1991 & - & - & 9 & - & - & - & - & - & 9 & 1,2 \\
\hline 1992 & - & - & 1 & - & - & - & - & - & 1 & 0,13 \\
\hline 1993 & - & - & 2 & - & - & - & - & - & 2 & 0,27 \\
\hline 1994 & - & - & 2 & - & - & - & - & - & 2 & 0,27 \\
\hline 1995 & - & - & 1 & - & - & - & - & - & 1 & 0,13 \\
\hline 1996 & - & - & - & 1 & - & - & - & - & 1 & 0,13 \\
\hline 1997 & - & - & 6 & - & - & - & - & - & 6 & 0,8 \\
\hline 1998 & - & - & 12 & - & - & - & - & - & 12 & 1,6 \\
\hline 1999 & - & - & 5 & - & - & - & - & - & 5 & 0,7 \\
\hline 2000 & - & - & 14 & - & - & - & - & - & 14 & 1,9 \\
\hline 2001 & - & 1 & - & - & - & - & - & - & 1 & 0,13 \\
\hline 2002 & - & - & 28 & 1 & - & - & - & - & 29 & 4,0 \\
\hline 2003 & - & - & 13 & 1 & - & - & - & - & 14 & 1,9 \\
\hline 2004 & - & - & 31 & 4 & 1 & - & - & - & 36 & 4,9 \\
\hline 2005 & - & - & 10 & 3 & - & - & - & - & 13 & 1,8 \\
\hline 2006 & - & - & 30 & 7 & 3 & - & - & - & 40 & 5,3 \\
\hline 2007 & 1 & - & 15 & 8 & - & - & - & - & 24 & 3,2 \\
\hline Total & 23 & 4 & 656 & 29 & 21 & 3 & 2 & 1 & 739 & - \\
\hline Percentagem & 3,1 & 0,5 & 88,7 & 4,0 & 2,9 & 0,4 & 0,27 & 0,13 & - & 100 \\
\hline
\end{tabular}


No ano de 1986 ocorreu o maior número de casos positivos de raiva bovina $(n=197)$ no período examinado. Nas demais espécies animais (eqüinos, ovinos e suínos), ocorreram apenas episódios isolados, indicativos de que provavelmente estes serviram de eventuais fontes de alimentação a morcegos hematófagos, dando margem assim à infecção.

Observa-se também um aumento no número de casos positivos em quirópteros a partir de 2002 (Quadro 3).

\section{DISCUSSÃO}

Estes dados, se analisados juntamente com os resultados de trabalho anterior (Roehe et al. 1987), apresentam um retrato fiel da casuística da raiva no Estado em 23 anos de trabalho. Neste período, a metodologia utilizada para o diagnóstico de raiva sofreu significativas mudanças. Nos primeiros anos desse estudo ainda era utilizada a técnica de detecção de corpúsculos de Negri pelo método de Sellers (Mayr \& Guerreiro 1972), mas esta foi gradualmente abandonada em função da maior sensibilidade e especificidade oferecidas pela IFD. A qualidade dos microscópios de fluorescência foi sensivelmente melhorada, de tal forma que a IFD atingiu sensibilidade e especificidade próximas a $100 \%$, sendo seu resultado tomado como parâmetro para orientação de tratamento.

Apesar de ser considerado muito estável genética e antigenicamente, o VR apresenta diferenças entre amostras isoladas de diferentes espécies, as quais são denominadas "variantes". É importante salientar que os perfis antigênicos detectados são bastante estáveis, pois, mesmo após uma passagem do vírus no hospedeiro acidental (tal como é o caso de amostras de origem de morcegos hematófagos em bovinos) ou inoculação experimental em camundongos, os resultados dos testes se mantêm inalterados podendo assim, indicar a fonte de infecção.

Apesar do registro de raiva em canino em 2007 no município de Tapes, RS (Caldas et al. 2007), a raiva canina urbana encontra-se controlada desde 1988, ano em que ocorreu o último caso de raiva associado a variante canina no Estado.

Uma tendência à diminuição dos casos de raiva canina no Estado já se verificava desde 1982, de acordo com estudos prévios (Roehe et al. 1987). Apesar disso, a despeito da ausência de casos de raiva canina, em 1990, um felino foi diagnosticado positivo; aquele achado foi, à época, muito preocupante, pois sugeria um possível ressurgimento da variante canina - fonte de infecção usual de felinos domésticos - em situação endêmica. Entretanto, tal caso provavelmente foi originado a partir de contato com morcegos, uma vez que inexistia raiva canina no entorno do foco. Infelizmente, naquela época, os métodos de análise genômica e molecular ainda não estavam disponíveis e a amostra foi perdida, pelo que a origem da infecção naquele caso pode somente ser estimada. Por outro lado, em 2001, ocorreu um novo caso de raiva em um felino em São Lourenço do Sul, RS. Naquele evento, pelo uso de análises com anticorpos monoclonais e estu- dos genômicos foi possível demonstrar que a fonte de infecção mais provável teria sido um morcego insetívoro Tadarida brasiliensis (Schaefer et al. 2002).

Da mesma forma, a variante isolada de um canino em 2007 apresenta um perfil antigênico e genômico encontrado em VR de morcegos insetívoros (Tadarida brasiliensis). Assim, estas variantes aparentemente não estão relacionadas à perpetuação da raiva em cães em forma endêmica, evidenciando o caráter incidental dessa contaminação. Assim, apesar de eventuais episódios isolados de contaminação com variantes de outros hospedeiros naturais, as evidências indicam que o vírus não se encontra circulando endemicamente em cães no Rio Grande do Sul desde 1988.

Apesar do êxito no controle da raiva canina, a raiva bovina segue sendo endêmica no Estado. Em um estudo anterior foi possível verificar uma tendência à ocorrência da raiva em bovinos em ciclos com intervalos variáveis, que nesta região situavam-se entre 8 e 11 anos (Nunes et al. 1982, Roehe et al. 1987). De 1985 a 2007 pode-se observar um pico de diagnósticos positivos no ano de 1986, com uma sensível tendência à queda nos anos subseqüentes, atingindo 1-2 casos/ano no período de 1992 a 1996. Nos anos seguintes, muito provavelmente em função da intensificação do programa nacional de controle da raiva dos herbívoros, implantado no País desde 1966 (MAPA 2008), o número de diagnósticos positivos em bovinos se manteve numericamente em níveis bem mais baixos do que nos anos anteriores. Porém observa-se a partir de 1999 uma característica cíclica, no entanto com picos de diagnósticos positivos verificando-se nos anos pares entre 1996 e 2006. Esse resultado está de acordo com o proposto por Turner (1975), o qual observou que em regiões endêmicas a cada 2 a 3 anos ocorrem surtos limitados à população de morcegos. Certamente ocorre sub-notificação dos casos de raiva em herbívoros, em função de que freqüentemente um caso índice é submetido ao laboratório, embora a submissão de outros casos do mesmo surto por vezes não seja realizada. Assim, torna-se muito difícil determinar o número real de perdas associadas à doença. Não obstante, a queda no número de diagnósticos positivos revela uma tendência à redução do número de casos, embora a enfermidade permaneça endêmica no Estado.

Nos últimos anos verificou-se um aumento do número de casos de raiva diagnosticados em quirópteros. Essa mudança pode estar relacionada a vários fatores, tais como alterações no meio ambiente, nas relações vírus/ hospedeiro ou ainda - e, na opinião dos autores, o mais provável nesse caso - na mudança de comportamento dos profissionais encarregados da submissão de materiais para diagnóstico. $O$ aumento da conscientização a respeito do papel dos morcegos no ciclo da raiva foi provavelmente a principal razão para este aumento no número de espécimes submetidos a diagnóstico - um fenômeno verificado em todo o território nacional (Batista et al. 2007). Face ao reduzido número de amostras de 
quirópteros que eram submetidas a exame nos anos passados, não estão disponíveis dados para permitir uma análise mais adequada de eventuais alterações na relação vírus/hospedeiro, particularmente entre morcegos hematófagos e bovinos. Em outras regiões do País, nos anos 2004 e 2005, os morcegos hematófagos tornaramse os mais freqüentes transmissores de raiva à espécie humana, revelando uma nítida alteração na escolha da fonte de alimento de parte dos quirópteros naquele determinado nicho (Da Rosa et al. 2006). No Rio Grande do Sul, alterações semelhantes não foram observadas até o presente.

Apesar do morcego hematófago, Desmodus rotundus, continuar sendo a principal fonte de infecção da raiva para os herbívoros, tem se tornado preocupante a identificação do vírus em morcegos não hematófagos em ambientes urbanos (Favoretto et al. 2002, Teixeira et al. 2005). O convívio dessas espécies com humanos em cidades dá margem à possibilidade de contato acidental com pessoas (Kotait 1996). Até o presente, não há nenhum registro de caso de raiva humana comprovadamente associada com transmissão a partir de morcegos não hematófagos no Brasil (SIEPI 2007), mas esta possibilidade requer que seja mantida uma constante vigilância sobre incidentes envolvendo contatos eventuais com morcegos de quaisquer espécies.

Tal como demonstrado com outros hospedeiros naturais do vírus, amostras de vírus da raiva isoladas de morcegos não hematófagos apresentam-se como variantes com adaptações espécie-específicas (Favoretto et al. 2002, Teixeira et al. 2005). Apesar disso, ocasionalmente, têm sido identificadas amostras isoladas de morcegos não hematófagos, porém com características de amostras de vírus de morcegos hematófagos. As evidências indicam que esse tipo de transmissão (hematófago para não hematófago) não é a regra, pois na maior parte dos casos as amostras isoladas de morcegos não-hematófagos detêm particularidades genômicas e antigênicas peculiares, que sugerem que tais amostras vêm co-evoluindo com espécies não-hematófagas há muitos anos. Estas últimas, portanto, não são casos de eventual contaminação incidental (Badrane \& Tordo 2001, Schaefer et al. 2005). Apesar disso, embora já seja possível identificar algumas das características dessas variantes, pouco se sabe a respeito da epidemiologia da infecção em morcegos não hematófagos. Além disso, a determinação de taxas de prevalência da infecção entre os membros destas espécies é difícil; estima-se que esta seja baixa, provavelmente entre 1\% e $3 \%$ dos espécimes "doentes" (isto é, com alguma alteração de comportamento) capturados. É importante, pois, que seja incrementada a vigilância epidemiológica sobre a raiva em morcegos não hematófagos, para que se tenha um maior conhecimento da biologia do vírus nestas espécies e para que se minimizem as chances de transmissão acidental, particularmente a humanos.

Por outro lado, a raiva nas demais espécies animais (eqüinos, ovinos, suínos e animal silvestre) onde o vírus tem sido ocasionalmente identificado, não tem se constituído em um problema significativo no Estado uma vez que estes casos têm sido originados mais provavelmente a partir de exposições acidentais a morcegos hematófagos. Como há geralmente abundância de gado bovino na região, fontes de alimento preferencial destes, outras espécies tornam-se opções alternativas de alimento aos morcegos hematófagos, sendo procuradas como fontes de alimento somente na ausência de bovinos.

\section{CONCLUSÕES}

A análise dos resultados dos diagnósticos de raiva realizados no Rio Grande do Sul nos últimos 23 anos revela que a variante canina do vírus rábico encontra-se sob controle efetivo, tendo o último caso sido registrado no Estado no ano de 1988. A raiva em morcegos hematófagos tem se mostrado mais resistente às tentativas de controle e permanece endêmica, assim como a raiva em bovinos, embora haja uma tendência à diminuição destes últimos casos. A partir de 2002 houve um aumento no número de submissões de amostras de morcegos (hematófagos e não hematófagos) para diagnóstico. Com isso, houve um aumento no número de casos positivos identificados nestas espécies a partir daquele ano. Entretanto, isso pode ser apenas conseqüente ao maior número de amostras examinadas, não refletindo necessariamente alterações na biologia do vírus ou de seus hospedeiros.

Agradecimentos.- A todos os funcionários do IPVDF que participaram do diagnóstico de raiva durante o período analisado neste trabalho. Apoio financeiro do Governo do Estado do Rio Grande do Sul através da Secretaria de Ciência e Tecnologia, FEPAGRO, CNPq, FAPERGS e CAPES

\section{REFERÊNCIAS}

Badrane H. \& Tordo N. 2001. Host switching in lyssavirus history from the chiroptera to the carnivora orders. J. Virol. 75:8096-8104.

Batista H.B.C.R., Franco A.C. \& Roehe P.M. 2007. Raiva: uma breve revisão. Acta Scient. Vet. 35(2):125-144.

Batista H.B.C.R., Caldas E., Maletich D.J., Franco A.C., Rijsewijk F.A.M., Teixeira T.F., Ferreira J.C., Rosa J. \& Roehe P.M. 2008. Canine rabies in Rio Grande do Sul caused by an insectivorous bat rabies virus variant. Revista de Saúde Pública. (Submetido)

Caldas E., Predebon J., Diedrich G., Farinatti A., Barreto N., Campielo P., Kessler S., Magoga E., Irigaray G., Carrieri M.L., Batista H., Rosa J., Ferreira J.C. \& Roehe P.M. 2007. Descrição do achado de raiva canina por vírus rábico de origem em morcego não hematófago Tadarida brasiliensis. Bolm Epidemiol. 9(2):1-3.

Da Rosa E.S., Kotait I., Barbosa T.F., Carrieri M.L., Brandão P.E., Pinheiro A.S., Begot A.L., Wada M.Y., De Oliveira R.C., Grisard E.C., Ferreira M., Lima R.J., Montebello L., Medeiros D.B., Souza R.C., Bensabath G., Carmo E.H. \& Vasconcelos P.F. 2006. Bat-transmitted human rabies outbreaks, Brazilian Amazon. Emerg. Infect. Dis. 12:1197-1202.

Dean D.J., Abelseth M.K. \& Atanasiu P. 1996. The fluorescent antibody test, p.88-93. In: Meslin F.X., Kaplan M.M. \& Koprowski H. (Ed.), Laboratory Techniques in Rabies. $4^{\text {th }}$ ed. World Health Organization, Geneva. 
Favoretto S.R., Carrieri M.L., Cunha E.M.S., Aguiar E.A.C., Silva L.H.Q., Sodré M.M., Souza M.C.A.M. \& Kotait I. 2002. Antigenic typing of Brazilian rabies virus samples isolated from animals and humans, 19892000. Mem. Inst. Med. Trop. São Paulo 44:91-95.

Germano P.M.L. 1994. Avanços na pesquisa da raiva. Saúde Públ. 28:86-91.

Heinemann M.B., Fernandes-Matioli F.M.C., Cortez A., Soares R.M., Sakamoto S.M., Bernardi F., Ito F.H., Madeira A.M.B.N. \& Richtzenhain L.J. 2002. Genealogical analyses of rabies virus strains from Brazil based on N gene alleles. Epidemiol. Infect. 128:503-511.

Kaplan M.M., Koprowski H. \& Meslin F.-X. 1996. Laboratory Techniques in Rabies. $4^{\text {th }}$ ed. World Health Organization, Geneva. 476p.

Koprowski H. 1996. The mouse inoculation test, p.80-86. In: Meslin F.X., Kaplan M.M. \& Koprowski H. (Ed.), Laboratory Techniques in Rabies. $4^{\text {th }}$ ed. World Health Organization, Geneva.

Kotait I. 1996. Infecção de morcegos pelo vírus da raiva. Bol. Inst. Pasteur, São Paulo, 1:51-58.

MAPA (Ministério da Agricultura, Pecuária e Abastecimento) 2008. http:/ /www.agricultura.gov.br/portal/page?_pageid=33,3271386 \&_dad=portal\&_schema=PORTAL. Acesso em 31.3.2008.

Mayr A. \& Guerreiro M.G. 1972. Vírus da raiva, p.301-317. In: Mayr A. \& Guerreiro M.G. (Ed.), Virologia Veterinária. $2^{\underline{a}}$ ed. Editora Sulina, Porto Alegre, RS.

Nunes J.C.C., Azevedo C.A.P. \& Rodrigues I. 1982. Combate à raiva dos herbívoros e caninos no Rio Grande do Sul. Lavoura/Pecuária 21:24-27.
Pantoja L.D. 1995. Caracterização de amostras brasileiras do vírus rábico com anticorpos monoclonais. Dissertação de Mestrado em Ciências Veterinárias, Faculdade de Veterinária, Universidade Federal do Rio Grande do Sul, Porto Alegre. 96p.

Roehe P.M., Schaefer R. \& Pereira A.S. 2002. Otimização da imunofluorescência direta para diagnóstico de raiva. Acta Sci. Vet., Porto Alegre, 30:53-57.

Roehe P.M., Cunha A.C., Rodrigues R.R., Gonçalves A.R. \& Ribeiro C.L.G. 1987. Diagnóstico laboratorial de raiva no Rio Grande do Sul, Brasil. Bolm Of. Sanit. Panam. 112(5):464-475.

Roehe P.M., Pantoja L.D., Schaefer R., Nardi N.B. \& King A.A. 1997. Analysis of Brazilian rabies virus isolates with monoclonal antibodies to lyssavirus antigens. Braz. J. Microbiol. 28:288-292.

Schaefer R., Batista H.B., Franco A.C., Rijsewijk F.A. \& Roehe P.M. 2005. Studies on antigenic and genomic properties of Brazilian rabies virus isolates. Vet. Microbiol. 107(3-4):161-70.

Schaefer R., Caldas E., Schmidt E. \& Roehe P.M. 2002. First case of cat rabies in southern Brazil for 11 years. Vet. Rec. 150:216-217.

SIEPI 2007. Sistema de Informação Epidemiológica. Panaftosa, OPAS, OMS. Disponível em: http://siepi.panaftosa.org.br/Anuais.aspx Acessado em 9.4.2007.

Teixeira T.F., Batista H.B.C.R., Schmidt E. \& Roehe P.M. 2005. Estudo antigênico de amostras do vírus da raiva isoladas no Rio Grande do Sul, Brasil. Acta Scient. Vet., Porto Alegre, 33:271-275.

Turner D. 1975. The Vampire Bat. Johns Hopkins University Press, London. 145p. 